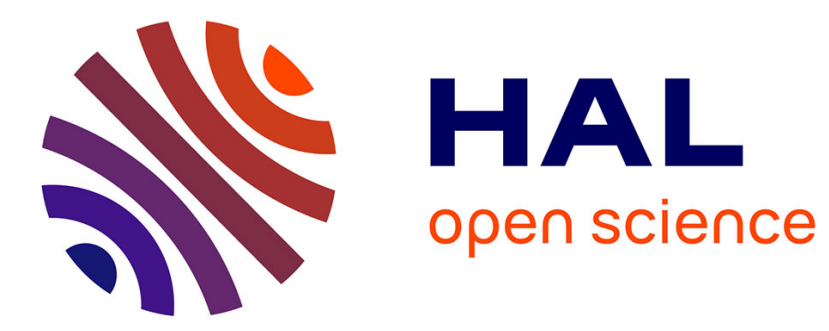

\title{
Retail Fabric Assessment: Describing retail patterns within urban space
}

Alessandro Araldi, Giovanni Fusco

\section{To cite this version:}

Alessandro Araldi, Giovanni Fusco. Retail Fabric Assessment: Describing retail patterns within urban space. Cities, 2019, 85, pp.51-62. 10.1016/j.cities.2018.11.025 . hal-02557289

\section{HAL Id: hal-02557289 \\ https://hal.science/hal-02557289}

Submitted on 6 Feb 2022

HAL is a multi-disciplinary open access archive for the deposit and dissemination of scientific research documents, whether they are published or not. The documents may come from teaching and research institutions in France or abroad, or from public or private research centers.
L'archive ouverte pluridisciplinaire HAL, est destinée au dépôt et à la diffusion de documents scientifiques de niveau recherche, publiés ou non, émanant des établissements d'enseignement et de recherche français ou étrangers, des laboratoires publics ou privés. 
Reference to the published version :

Araldi A., Fusco G., Retail Fabric Assessment: describing retail patterns within urban space. Cities, 85(2019), 51-62

https://doi.org/10.1016/j.cities.2018.11.025

\title{
Retail Fabric Assessment: Describing retail patterns within urban space
}

\author{
Alessandro Araldi, Giovanni Fusco \\ Université Côte-Azur, CNRS, ESPACE, 98 bd Edouard Herriot, BP 3209, 06200 Nice, France
}

\begin{abstract}

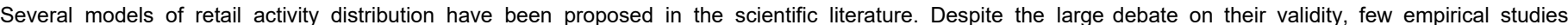

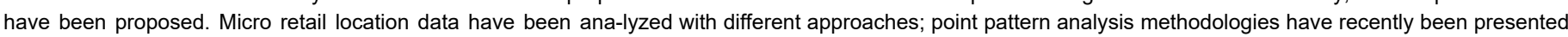

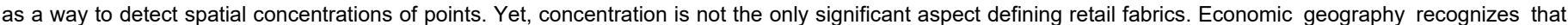

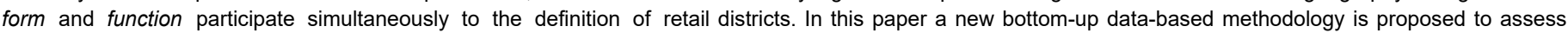

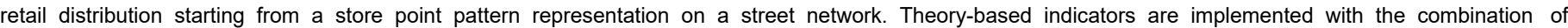

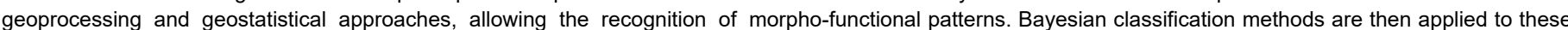

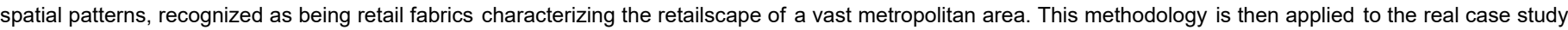
of the French Riviera metropolitan region. Retail fabrics and their spatial organization are identified and described.
\end{abstract}

\section{Keywords:}

Retail distribution, Retail fabrics, Geoprocessing,

Point pattern analysis, Bayesian classification

\section{Introduction}

The presence of retail activity within urban space is of paramount importance to street and neighborhood attractiveness: it enhances social and economic exchanges between citizens, contributing to the dynamics of a city (Gehl, 1987; Jacobs, 1961). Despite the undeniable growing importance of new communication technologies and their impact on citizen behavior, internet is "a pale imitation of [...] real proximity" (Greenberg, 1995).

Spatial distribution of retailers within settlements reveals information on the socio-economic characteristics of the population living and working in those spaces: consumers' needs and desires are satisfied by the diversity of stores and merchandise offered in a neighborhood (Cachinho, 2014). The aggregate choices of consumers shape the overall patterns of retail activities (Craig, Ghosh, \& McLafferty, 1984). Moreover, the social activity generated by the presence of retailers contributes not only to the concept of safety and control of the urban space ("eyes on the street" (Jacobs, 1961)) but also to the non-monetary concept of gift-value (Greenberg, 1995).

Awareness of the role of retail presence in urban space is now a well-established value for planners. Indicators of retail presence have been also incorporated in street/neighborhood measurement for real estate value estimation (i.e. Walk Score in USA, ${ }^{1}$ CityScan in France, ${ }^{2}$ etc.).

Nevertheless, a simple enumeration of stores and businesses within a street, or a given urban space, "does not tell the whole story" (Greenberg, 1995). Descriptors of spatial distribution as well as variety of retail typology contribute in different ways to the strength and the appeal of a commercial district. The combination of these character-istics should be interpreted as a local DNA of the socioeconomic fabric representing both the outcome and the determinant of the surrounding urban nature (Brown, 1994; Craig et al., 1984; Hillier, 1996).

Starting from Central Place Theory, researchers deducted and de-bated different spatial representations and models of retail distribution within urban settlements (Berry, 1963; Burns, 1959; Davies, 1974; Guy, 1994; Proudfoot, 1937). Constantly evolving technological progresses are modifying and multiplying citizens' shopping behaviors, with a re-sulting observable impact in retail distribution and composition within urban space (Desse \& Lestrade, 2016). Despite the important heritage of traditional models and approaches still influencing current retail dis-tribution and urban planning policies (Brown, 1991; Saraiva \& Pinho, 2017), new paradigms need to be investigated in order to consider the impact of modern socioeconomic tendencies. Quantitative urban geo-graphy, thanks to ever-growing data availability and powerful

\footnotetext{
${ }^{1}$ https://www.walkscore.com

${ }^{2}$ https://www.cityscan.fr/
} 
geoprocessing tools is well positioned for the study of urban patterns (Carol, 1960) especially in a large scale approach.

The study of retail distribution within settlements (retailscape, (Cachinho, 2014)) is not merely a descriptive task. Identifying retail fabric patterns and their spatial configuration represents the first step for the elaboration of new urban planning development and regeneration projects. Furthermore, it might represent an essential variable for locational decision and modeling of retailers.

Within this context, the goal of our paper is to propose a new geoprocessing methodology for store point pattern analysis on the urban street network. Retail Fabric Assessment (RFA) is based on senior the-oretical models but allows the identification and characterization of urban retail localization patterns in a whole metropolitan area, with a micro-scale bottom-up approach, using automated geo-processing. With a real-world application to the case study of the French Riviera, the paper will show the kind of results that the new methodology is able to produce. We think that the insight into retail distribution in the city provided by RFA could open new perspectives for retail policies within metropolitan areas.

The paper is structured as follows. Section 2 reviews scientific literature on retail pattern analysis, focusing on the two main approaches: hierarchical and post-hierarchical models. Section 3 reviews recent empirical works on retail micro-scale analysis, considering both theoretical and empirical studies. Section 4 specifies the objectives of the methodology proposed in this paper. Section 5 presents the RFA methodology. Its application to the real case study of the French Riviera is discussed in Section 6 . Conclusion and perspectives of future work are discussed in the final section.

\section{Retail patterns, models}

Models of commercial distribution within settlements have been strongly inspired by land-use theories developed at the beginning of the twentieth century. Proudfoot (Proudfoot, 1937) transposed the concepts of Central Place Theories (CPT) to the intra-urban retail distribution. Based on detailed studies of several American cities, this author proposed the first spatial representation of commercial structure through the definition of five categories of retail districts: Central Business District (CBD), outlying business centers, principal business thoroughfare, neighborhood business street and isolated store clusters. Similarly, Carol's analysis (Carol, 1960), revised CPT at the intra-urban system of Zurich: here again, a hierarchical representation of com-mercial districts on four levels is described.

The most studied and discussed scheme is the Berry's hierarchical model (Berry, 1963). The analysis of the business districts of Chicago led this author to identify three morpho-functional groups: (i) nested hierarchical centers, (ii) commercial ribbons and (iii) specialized areas (Fig. 1). Each of these groups is divided in subgroups considering size and complexity of the retail structure. While the first group follows Carol's fourfold subdivision, the other two represent the most inter-esting advance of Berry's model. Ribbon developments identify those store concentrations with a linear layout alongside highways, routes, urban roads with or without a functional specialization (i.e. home supplies, furniture decoration etc.; motorcar industry related etc.). Specialized areas represent large areas with a specific retail or service function concentration.

For about 30 years, this theoretical model has been celebrated but also criticized due to its several underlying assumptions and implications (Dawson \& Sparks, 1986). Despite evolutions in the socio-economic settings and in retail, Berry's model has been applied by students, town planners and retailers themselves (Brown, 1992; Brown, 1993). Ever since the ' 80 s several studies identified issues with this model: the incomplete picture of spatial patterns of urban retailing (Jones \& Simmons, 1990; Potter, 1982), the assumption of single-purpose shopping behavior (Dawson, 1983) and single-retail organization (Dawson, 1983; Guy, 1984), the new development of big box stores out-of-town
(Davies, 1984) etc. Dawson and Kirby (1980) and Dawson and Sparks (1986) state the inadequateness of Berry's hierarchical model.

Consequently, several post- and quasi- hierarchical models have been proposed to address these criticisms. Brown's (1991) taxonomy represents an interesting evolution of the hierarchical model. The starting point of Brown's classification is based on the identification of two main aspects describing retail districts: the form of a shopping area and its function. Three types of form can be recognized: cluster, linear and small isolated concentrations. The function of these agglomerations is then considered: general, specialized or ancillary functions are thus identified. The combination of these two factors, generates a classifi-cation matrix composed by 9 groups of commercial districts, extended to 12 when considering planned/unplanned clusters (Fig. 2). At the end of his work, Brown highlights some limitation of his method. Firstly, the difficulties in the identification of the 12 classes described by the post-hierarchical model in real case studies. Second, the model represents a static classification unable to recognize changes in the retail configuration. Finally, Brown highlights that despite its exclusion, "hierarchy still exists and will doubtless continue to exist" ((White, 1975), p377).

While hierarchical models were developed during a period in which city centers represented the socio-economical core of settlements, post hierarchical models emerged during post-war suburbanization (second revolution of retail distribution, (Desse \& Lestrade, 2016)).

Several empirical studies have been applied and adapted to intraurban case studies (Brown, 1993; Davies, 1972; Potter, 1982) or focusing on specific retail agglomerations. Nevertheless, researchers constantly highlight the need of more empirical quantitative analysis of different retail agglomerations and categories within a common fra-mework (Brown, 1994; Davies, 1972; Fleury, Mathian, \& Saint-Julien, 2012; Merenne-Schoumaker, 2008).

\section{Different quantitative approaches to micro retail location}

A growing number of quantitative studies in urban geography and urban planning explored the relationships between urban form and socioeconomic characteristics within a city. More particularly parameters of the urban physical environment and retail distribution have been studied considering different morphological components: network configuration (as for example (Hillier et al., 2003; Porta et al., 2009)) and morphological analysis of elements such as buildings, parcels, blocks and their spatial arrangement (Saraiva \& Pinho, 2017; Yoshida \& Omae, 2005). While the former group proposes an advanced elaboration of proximity, accessibility and centrality-based approaches at the intra-urban level, the latter investigates the influence on retail distribution of the physical layout of the urban space.

Both these paths of research propose a large variety of methodological approaches and techniques highlighting different spatial properties of the urban form. But when it comes to cross analyzing these properties with retail distribution, the simple density/presence of stores is considered. As discussed in the introduction, the combination of spatial distribution and functional mix at the origin of the retail system should not be reduced to simply counting the number of stores in a given space. Just like built-up density has been criticized as being too simplistic to describe urban fabrics, we need to overcome an oversimplified assessment of retail in the city through the sole parameter of retail density. We thus propose to define the new concept of retail fabrics within the city, taking into account the most characteristic spatial and functional properties of retail distribution patterns within urban space and building on the aforementioned theories of retail geography in the city.

Only separate assessments of urban fabrics and retail fabrics might allow in a later phase of analysis, the study of the interrelations between these two aspects revealing the organization of the global form of a complex city as a whole.

Although retail distribution analysis has attracted researchers' attention on national, regional and urban scale since the beginning of the 


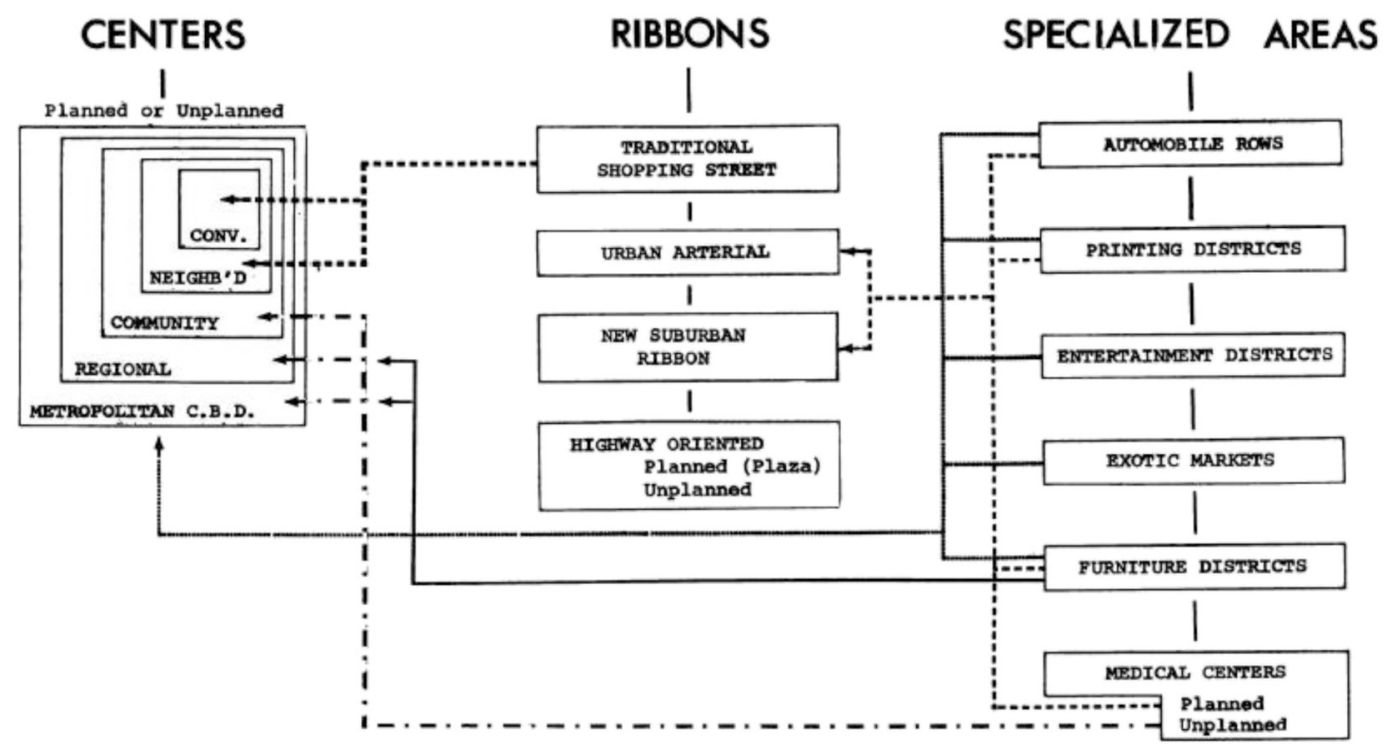

Fig. 1. Berry's hierarchical structure of business and commerce. Source: (Berry, 1963, Table:2).

\begin{tabular}{|c|c|c|c|c|}
\hline & \multicolumn{4}{|c|}{ FUNCTION } \\
\hline & & GENERAL & SPECIALIST & ANCILLARY \\
\hline \multirow{4}{*}{ FOAM } & $\begin{array}{l}\text { CLUSTER } \\
\text { (Unplanned) }\end{array}$ & $\begin{array}{l}\text { Town and City } \\
\text { Centres }\end{array}$ & $\begin{array}{l}\text { Bright Lights } \\
\text { District }\end{array}$ & $\begin{array}{l}\text { Sandwich Bars } \\
\text { in Financial District }\end{array}$ \\
\hline & $\begin{array}{l}\text { CLUSTER } \\
\text { (Planned) }\end{array}$ & Megacentre & $\begin{array}{l}\text { Speciality } \\
\text { Shopping Centre }\end{array}$ & $\begin{array}{l}\text { Shops in Airport } \\
\text { Departure Lounge }\end{array}$ \\
\hline & LINEAR & $\begin{array}{l}\text { Traditional } \\
\text { Arterial Route }\end{array}$ & $\begin{array}{l}\text { Ethnic } \\
\text { Shopping Street }\end{array}$ & Hamburger Alley \\
\hline & ISOLATED & Corner Shop & $\begin{array}{l}\text { Carpet } \\
\text { Warehouse }\end{array}$ & $\begin{array}{l}\text { Crush Bar in } \\
\text { Opera House }\end{array}$ \\
\hline
\end{tabular}

Fig. 2. Brown's non-hierarchical classification of retail location. Source: Brown (1991, Fig. 2).

20th century, micro retail location has been, comparatively, neglected (Brown, 1994) mainly because of the lack of precise location information of stores. Consequently, empirical studies have been forced to consider coarser scales at a given spatial unit, often represented by administrative boundaries (Fleury et al., 2012; Hidalgo \& Castañer, 2015). These partitions might be at the origins of statistical bias related to the well-known modifiable areal unit problem (MAUP, (Openshaw, 1984)). Aggregate statistics related to administrative boundaries could influence the choice of indicators and the resulting definition of business centrality of settlements. Asides from that, it seems to us that a clearer understanding of the spatial logics of retail distribution in the city should not ignore the main characteristic of urban space for pedestrians and retailers: urban space is a network space, and all administrative subdivisions ignore this very nature of urban spatiality.

Davies (1972) in his criticism of CPT, highlights how the difficulties of defining the extent of centers absorbed the attention of researchers, hindering empirical studies on retail structure typologies. Despite the conceptual clarity of Brown's post hierarchical model (Dawson \& Kirby, 1980) the empirical recognition of these classes is not easy.

Urban planners and practitioners aware of the importance of theoretical models and of the lack of well-established methodological procedures beyond traditional aggregate statistics, adopted classification measures of the urban retail spaces based on expert-based knowledge and observation of the space study under analysis. This practice requires qualitative approaches to identify, delineate and adapt theoretical patterns to each real case study. Discussions and criticisms of the obtained spatial partition might arise due to the subjectivity of this procedure.

A systematic, quantitative, bottom-up (even if partially theorydriven) approach for retail distribution assessment at the urban microscale is therefore needed for both modeling and assessment purposes. In order to achieve this goal, empirical studies resulting from economic geography theories need to be combined with methodological works from geo-statistics and point pattern analysis.

In Guy (1998), data-based classifications are presented as an im-portant means to "analyze relationships in the world of retailing". Two peculiarities are associated with this methodology: firstly, "logical and appropriate classification provides systematic and well-informed discussions of research in retail geography". Secondly, the possibility to compare empirical findings within different spaces, cultures and time periods. Guy resumes and discusses classifications based on three facets of re-tailing: consumer behavior choice, retail strategy and retail location. While the first two approaches consider intrinsic aspects of stores (type of goods, retail size etc.), the third focuses on their spatial distribution within settlements. Nevertheless, methodological implementations are not provided. 
Mackaness and Chaudhry (2011) propose an automatic classification of retail spaces from a large scale topographic database. They include descriptors of the configurational disposition of retailers, built-up and non-built-up spaces, to identify retail parks, shopping malls and agglomeration of high streets. This work represents one of the first examples of classification of retail concentrations considering different aspects of retail configuration. However, it focuses attention only on planned/unplanned concentration including non-retail information (distance from CBD, parking, etc.).

Vazquez (2011) applied k-means classification on eight configurational, form and dimension indicators. The spatial unit of this methodology, are clusters of retails (called "nodules") identified by a prespatial analysis based on concentration thresholds. Similarly, Delage and Fleury (2011) applied hierarchical ascendant classification on nodules defined by nearest neighborhood approaches.

Hidalgo and Castañer (2015) implement a recommender system to identify missing amenities considering current specialization patterns within neighborhoods. An ad hoc clustering algorithm is here implemented starting from a distance based accessibility indicator. Both agglomeration and specialization of amenities patterns are studied, but their analysis is not simultaneously considered. The analysis of the former results in a partition of space that, despite being endogenous, still imposes constrains on the determination of the latter (similar to what was discussed above for exogenous partitions). The delimitation of neighborhood partitioning impacts the commercial presence and typology mix, influencing the results of amenity typology correlations.

Other recent quantitative works on retail patterns present interesting methodological innovations based strongly on spatial statistics and geo-processing algorithms.

Jensen (2006) proposes a local appropriateness indicator for each retail activity in a specific location, considering store presence within its surrounding area. This indicator is based on quantitative measures of local spatial attractive/repulsive behaviors between retail categories, based on the $M$ (Duranton \& Overman, 2005; Marcon \& Puech, 2009). Jensen's local adaptation of the $M$ statistic is a first attempt to identify local over/under representation of retail activities and can be applied in retail pattern recognition.

Two considerations may be made in this respect: firstly, this procedure should consider network-based subspaces instead of Euclidean disks to fully consider the specificities of urban space. Euclidian-space techniques can generate false clusters of hot/cold spots when applied to phenomena taking place in a network constrained space (Okabe \& Yamada, 2001; Yamada \& Thill, 2004). While the $M$ statistic applied to industrial sites on a regional and national scale might not be strongly affected by street network configuration, the same cannot be said when dealing with retail activities within urban spaces. Secondly, retail fabric (as seen in the previous chapter) has been theoretically identified and described not only by its functional characteristics: concentration and spatial layout should also be considered.

The analysis of density based spatial clustering algorithms applied to retail distribution in the city represents the focus of Dolega, Pavlis, and Singleton (2016). In this paper spatial methods for point pattern clustering identification like k-means, quality threshold, KDE, random walk and density based spatial clustering of application with noise (DBSCAN) are applied and compared. Another variant of clustering analysis of point patterns, is represented by clumping methods. ${ }^{3}$ Okabe and Funamoto (2000) implemented a Planar Variable-Distance Clumping Method (PL-VCM) to identify statistical significant clumps at different scales. More recently, the corresponding network-based version (NT-VCM) has been proposed by Shiode and Shiode (2009).

DBSCAN and VCM methods represent two interesting and

\footnotetext{
${ }^{3} \mathrm{~A}$ clump, is defined as "a set of points on a plane where all the points are within a certain Euclidian distance of at least one other element of the set" (Okabe \& Funamoto, 2000)
}

statistically robust exploratory methods for point pattern clustering/ clumping identification. The spatial arrangement of a given set of points at different scales is compared to random distributions, in order to detect and extract clustering/clumping information pertaining only to anomalies, which means identifying elements that are unlikely to happen by chance. These methods are fundamental when spatial models of the phenomena under study are unknown or not available like road accidents, wildlife fatality, crime etc. In these examples, the determination of significant hot-spots leads to the identification of spatial aggregations where an exogenous cause might be investigated. As seen in the previous chapter, the distribution of retails in urban space shows specific functional-form patterns. Despite the fact that many statistical methods proposed in literature have been applied to retail distribution within cities, these methods always compare ob-served patterns to random distributions in order to corroborate the simple hypothesis of concentration/dispersion.

From the works reviewed in this section we can formulate the following observations: (i) Classifying retail fabrics in the city should be independent from physical elements of the urban settlements; the two phenomena must be analyzed and characterized independently if a crossanalysis of the relationship between them is later sought for. (ii) Partitioning retail points through clustering/clumping methodologies, by the means of thresholds or adopting exogenous administrative partitions could bias the results of the resulting functional correlations. (iii) Any fine-grained spatial analysis of retail should respect the network-space of the city. (iv) Data-based classification methods can produce more objective results and serve as a basis for comparative analysis and simulation models. ( $v$ ) The analysis of retail distribution cannot be reduced to a simple agglomeration analysis (Guy, 1998): form and function should be considered simultaneously. These observations are the rationale for a new methodological protocol, which will be presented in Section 5 .

\section{Case study}

The French Riviera metropolitan area, in Southern France (Fig. 3) will serve as a case study to test the new methodology on a real-world case study. With a population of more than one million inhabitants over $1500 \mathrm{~km}^{2}$, this space is a unique conjunction of natural and urban landscapes. The topography, with elevation ranging from the sea level up to $1700 \mathrm{~m}$ of the pre-Alps attracts a strong touristic and leisure presence both during summer and winter seasons. Traditional villages and suburban developments are spread around three high density urban areas. From east to west, we find: Monaco and its skyscrapers, the most densely populated sovereign nation in the world; the urban agglom-eration of Nice with a regular meshed core inspired by the Turin model (Graff, 2000) surrounded by residential, hilly and less tightly planned areas. And finally the urban agglomeration of CannesGrasse-Antibes characterized by land irregularity together with the carcentered sprawl development of the lasts 50 years. While historical centers present high concentration of touristic-based stores, peripheral areas collect a great number suburban ribbons and specialized areas scattered along the main connection axes. Another peculiarity is the presence of a strong and dynamic real estate market due to the presence of wealthy tourists willing to buy holiday homes inducing a strong presence of real estate agencies. The combination of all these elements produces a sequence of urban centers and peripheral areas of different sizes and different morphology with an uneven distribution of commercial activities.

Moreover, unlike examples found in scientific literature where often case studies are uniformly urbanized dense areas or monocentric cities and metropoles, the French Riviera is a coastal polycentric metropolitan region, with a large number of small- and average-sized villages and towns. Within this peculiar space, in the last fifty years, a great number of retail configurations have been generated from the combination of their spatial layout and specialization/mix properties.

The retail data include 33,000 commercial activities with a surface smaller than 300 square meters and 884 anchor stores with a surface over 


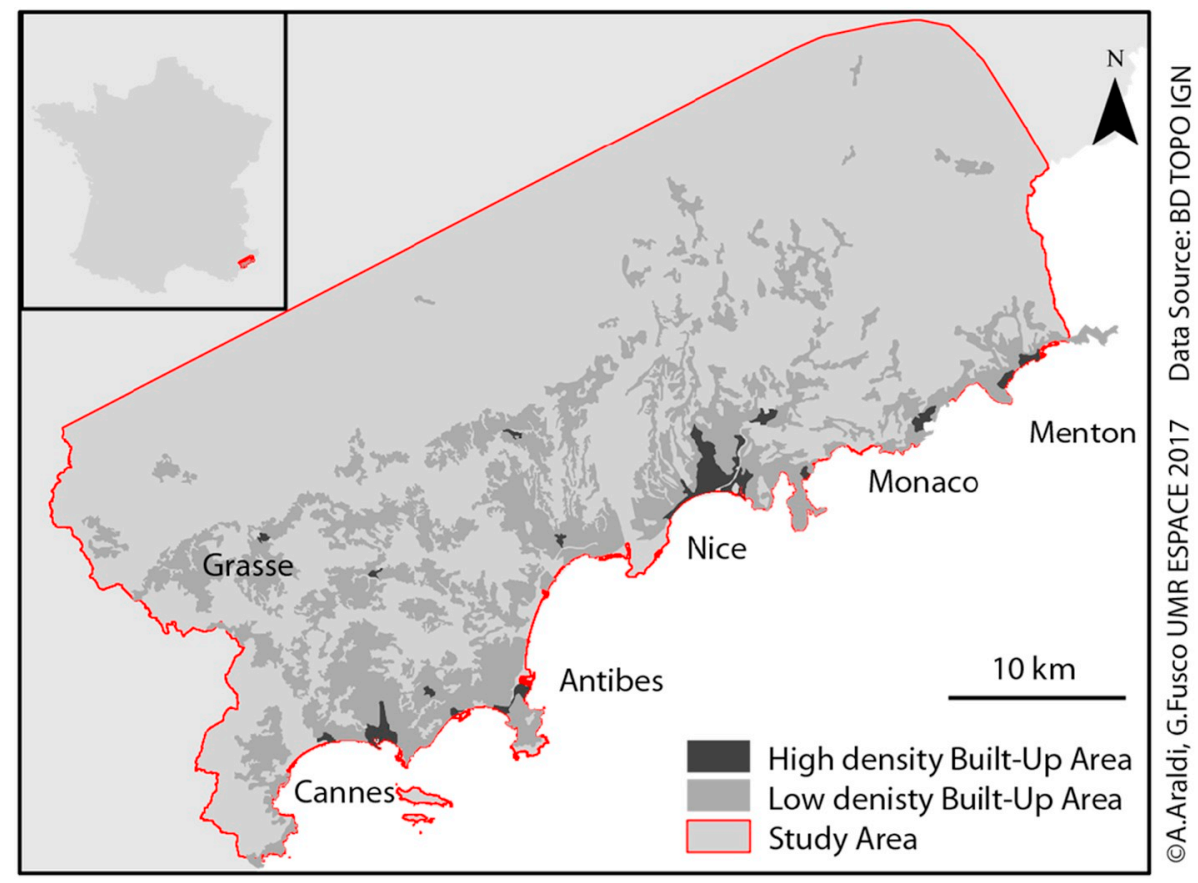

Fig. 3. The metropolitan conurbation of the French Riviera, France.

$300 \mathrm{~m}^{2}$ (2016). Each store is described by its precise location and a national retail classification code (French Nomenclature of Activities, NAF) with a direct correspondence to the European and International Classifications (NACE and ISIC). When the store exceeds 300 square me-ters, the precise extent of its surface is reported. This information is pro-vided by the local Chamber of Commerce ensuring a high degree of quality and exhaustiveness. In this study we will consider a classification of 12 retail categories with few adaptations in order to consider the economical specificities of our case study. The French National Geographic Institute (IGN) provides geographical information of the street network.

\section{Methodology}

We are thus looking for a new methodology producing an automated delimitation of retail fabrics within polycentric metropolitan areas without any preconceived or exogenous partition of space, any expert-based recognition of retail fabric, and being able to associate both functional and spatial characteristics within an acknowledged theoretical framework.

Together with these objectives, some methodological constrains are included: (a) Network constrained distances to respect the nature of retail distribution within the city; (b) Minimal and standardized information on retailers, required to guarantee the reproducibility and adaptability to other case studies.

Multiple Retail Assessment (MRA) is a three-step protocol for the analysis of retail distribution; it can be summed up as follows:

1. Defining a network constrained catchment area around each event and collecting retail activity information.

2. Identification of retail distribution patterns: (i) configurational properties, (ii) geometrical distribution (iii), local significant prevalence of retail typology;

3. Clustering of relative event-based patterns through Bayesian methods in order to identify and characterize retail fabrics.

\subsection{Spatial unit}

RFA inverts order of the analysis of traditional approaches. Instead of defining/identifying a spatial partition and analyze in a second phase the retail information within each subspace, RFA collects and analyzes different aspects of the retailscape surrounding each store (steps 12 ), and only afterwards identifies retail fabric types through classification methods (step 3). In other words, the classification is applied on the local patterns wherein the single observation is included, similarly to what happens when applying moving average methods on a shifting temporal/spatial subset.

The spatial unit on which MRA methodology is built, is the point representation of stores. Starting from their street network location, we consider a network-based catchment area at a given distance $r$. Within each subnetwork, the number of stores for each commercial typology is computed. This procedure is the starting point of many statistical methods (i.e. Ripley's $\mathrm{K}$ and derivatives etc.) exploring the distribution of points considering increasing values of $r$. While these works study the scale-dependence of point clustering behavior, RFA focuses on specific scales of analysis, relying on literature of store-to-store pedestrian movement.

\subsection{Form and functioning patterns}

Form and function represent the two main components of retail structure identified in the scientific literature. This section presents how these two aspects are conceptualized and implemented through quantitative algorithms based on statistical and geoprocessing methods. Finally, each unit is described by quantitative variables allowing the identification of form-function patterns of the surrounding retail structure.

In the following description of pattern recognition, three local levels have been separately associated to each indicator, depending on the enclosed information. We refer to them as: street level $(r=150$ $\mathrm{m})$, neighborhood level $(r=300 \mathrm{~m})$ and community level $(r=600 \mathrm{~m})$.

The local Form of retail activities is described by a set of three indicators:

- Relative Accessibility. For each store-point, we compute the total number of retailers $\mathrm{N}(\mathrm{r})$ within a given radius $r$. A segmentation based on quantiles is applied to the statistical distribution of $\mathrm{N}(\mathrm{r})$ on the overall study area. This discretization informs us on the relative importance of local retail accessibility. The procedure is applied at 


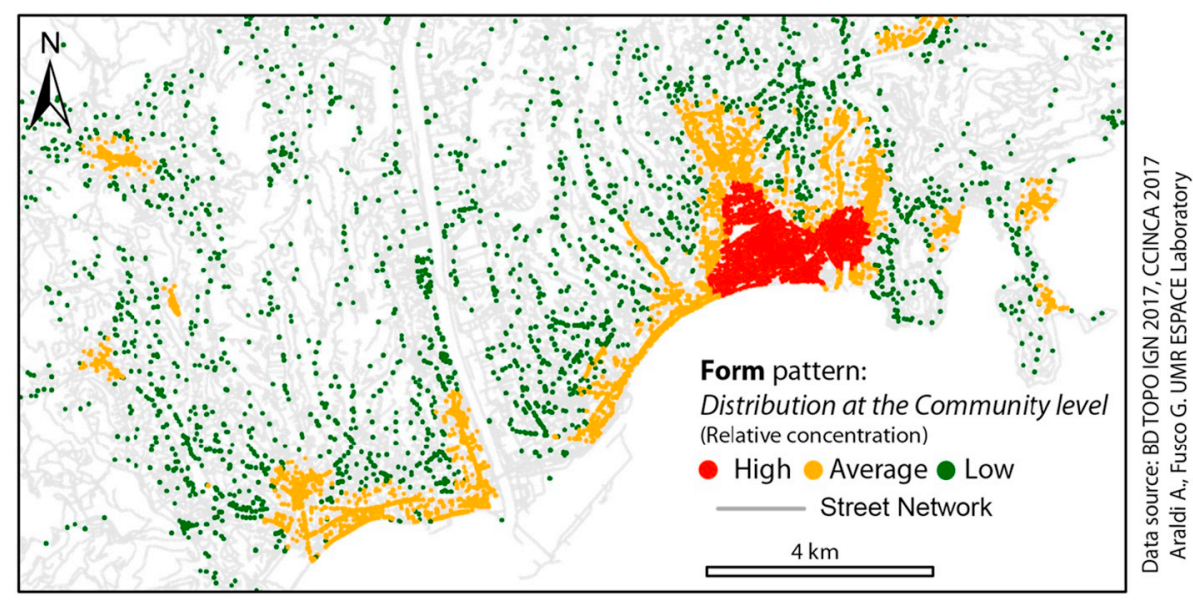

Fig. 4. Examples of Form Pattern distribution at the community level.

the three selected scales. For example, in Fig. 4, the patterns iden-tified illustrate the hierarchical importance of centers at the com-munity scale.

- Agglomeration considers the ratio of the number of stores at two different scales: street/neighborhood levels and neighborhood/ community levels. This indicator discloses the information on the aggregation of the retailscape at a given level compared to the larger one. We can thus detect isolated stores and high concentrations surrounded by empty/lower concentrations (High-Low distributions), lower retail presence close to high concentrations (Low-High) and homogenous distribution at both scales (High-High and LowLow). This triple description is obtained by applying the same discretization method used for the previous indicator.

- Geometry refers to the morphological nature as defined by Berry (1963). This indicator is obtained implementing the point pattern analysis methodology developed by Araldi and Fusco (2018). This procedure detects the local geometrical layout of a point pattern dataset on network implementing the functional sandbox counting method (Kanevski \& Pereira, 2017) developed in fractal studies. This procedure is here applied at the three aforementioned scales: at the street level, fragmented or linear continuity of stores can be detected. At the neighborhood and community levels, three geometrical layouts can be identified (Fig. 5): pervasive distribution, when the whole local subnetwork is equally filled by stores. Linear distribution describes the presence of a linear feature of retails compared to the overall distribution of the point subset. Fig. 5(d), shows how this methodology can identify as linear structures both traditional shopping streets within a city center and suburban ribbons. Finally, scattered store layouts are small and fragmented concentrations or isolated stores. All form indicators are based on the total store count at different radii. In order to identify the functional characteristics of a commercial district, the number of stores for each retail family is now analyzed. The local Functioning of a retail distribution is described by three in-dicators:

Retail category variety is described by the number of retail types present within the neighborhood distance. This indicator represents the amplitude of the commercial offer enabling a multi-purpose shopping behavior. Lower values of variety might represent both specialized areas and small convenience/street-corner developments.

Retail category prevalence aims at identifying significant patterns of specific function concentrations. As in Jensen (Duranton \& Overman, 2005), this indicator is based on the local implementation of the $M$ index (Okabe \& Yamada, 2001): it is obtained as the ratio between the total number of a specific store category and the total number of stores within a neighborhood distance. In order to evaluate the significance of particularly high or low prevalence values, this ratio is compared to the average of the ratios obtained considering each event of the point pattern. A double one-tailed binomial test is then applied with a confidence level of $0.95 .{ }^{4}$ The results of the application of this methodology to each group of the 12 retail typologies identify statistical High, Low and Not Significant patterns of functional prevalence (Fig. 6). As with the agglomeration indicator, the patterns of retail category prevalence represent a relative measure based on the overall distribution within the space study. Twelve retail categories are considered (Retail category prevalence Table 1).

\begin{abstract}
- Anchor store category prevalence. This group of indicators are introduced in the analysis to consider the presence of anchor stores in the retail ecosystem. The importance of these magnet/ attractor stores (Brown, 1994) requires a specific group of indicators to quantify their influence on smaller retailers and also those "out-of-town" store configurations, missing in the hierarchical models. The statistical analysis of category prevalence, applied above for small and average sized retail surfaces, is reiterated here considering surface information. The spatial influence of anchor stores covers wider spaces compared to small retailers; the prevalence measure is thus implemented at the community level. Six typologies of retail activities are analyzed (Anchor store category prevalence in Table 1)
\end{abstract}

\subsection{Recomposing and characterizing retail fabrics: Bayesian classification}

In order to identify retail fabrics, we still have to combine the results of the geo-statistical and morphology patterns.

Clustering approaches aiming at achieving high intra-cluster homogeneity based on variance minimization on the values of all the indicators are not well fitted for this task.

Bayesian inference method is based on conditional probabilities (Duda, Hart, \& Stork, 2001); this method tries to minimize the probability of error in a decision, by associating to each individual the most probable outcome. The advantage of this method is its ability of identifying classes based on subsets of indicators that could characterize a specific class. Fusco (2016) proposes Bayesian clustering to identify

\footnotetext{
${ }^{4}$ As discussed in the scientific literature, a Monte Carlo randomization of the points around each center of the analysis would be the best way to evaluate the correct local statistical significance of the "prevalence" computed within our methodology. Our case study would then require the implementation of one thousand Monte Carlo randomizations around 33 thousand centers of analysis.
} 

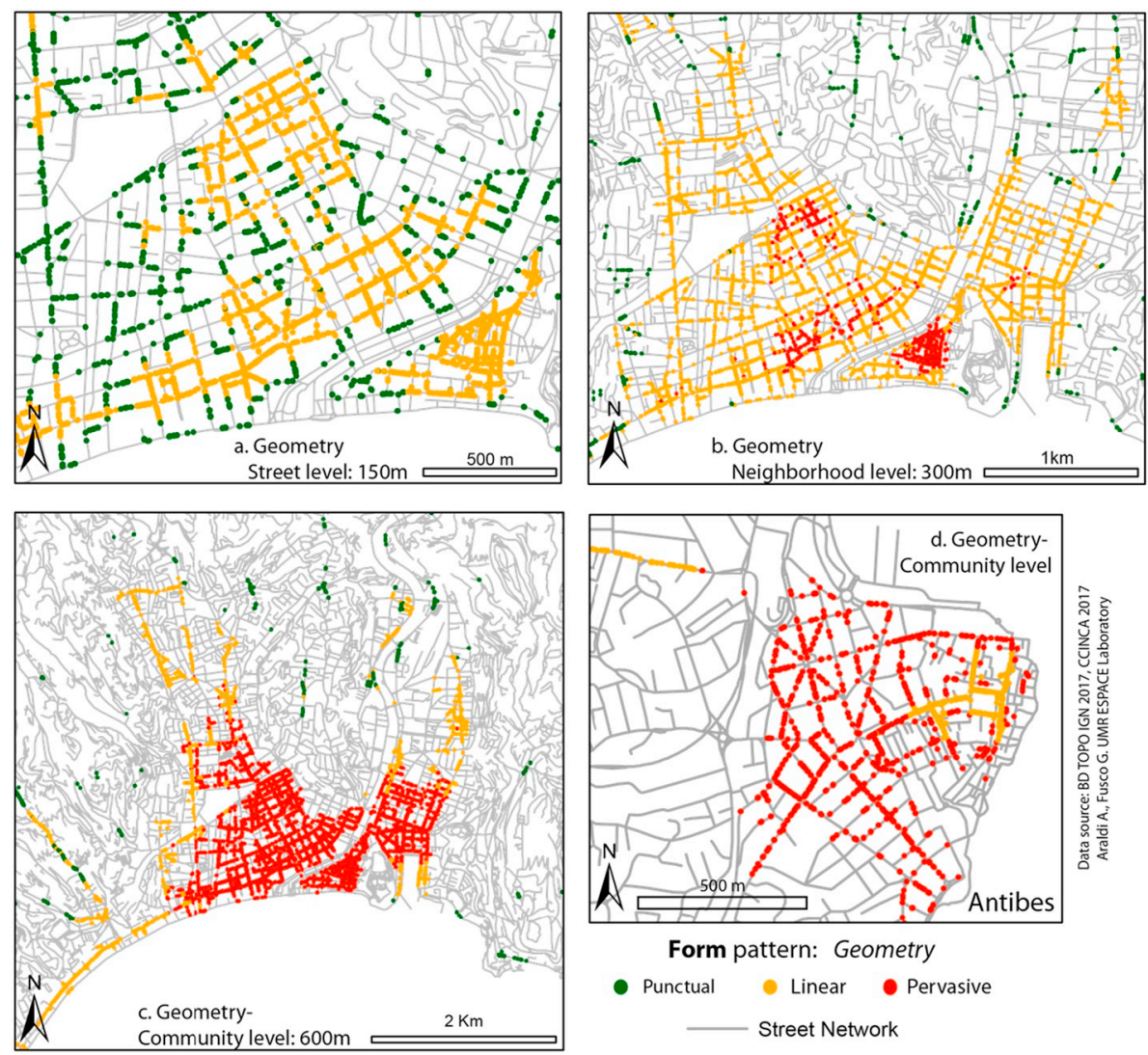

Form pattern: Geometry

- Punctual Linear Pervasive

- Street Network

Fig. 5. Form Pattern: Geometry at the street (a), neighborhood (b) and community (c) level. This indicator allows the identification of significant ribbons in both suburban and central areas as illustrated in Antibes (d).

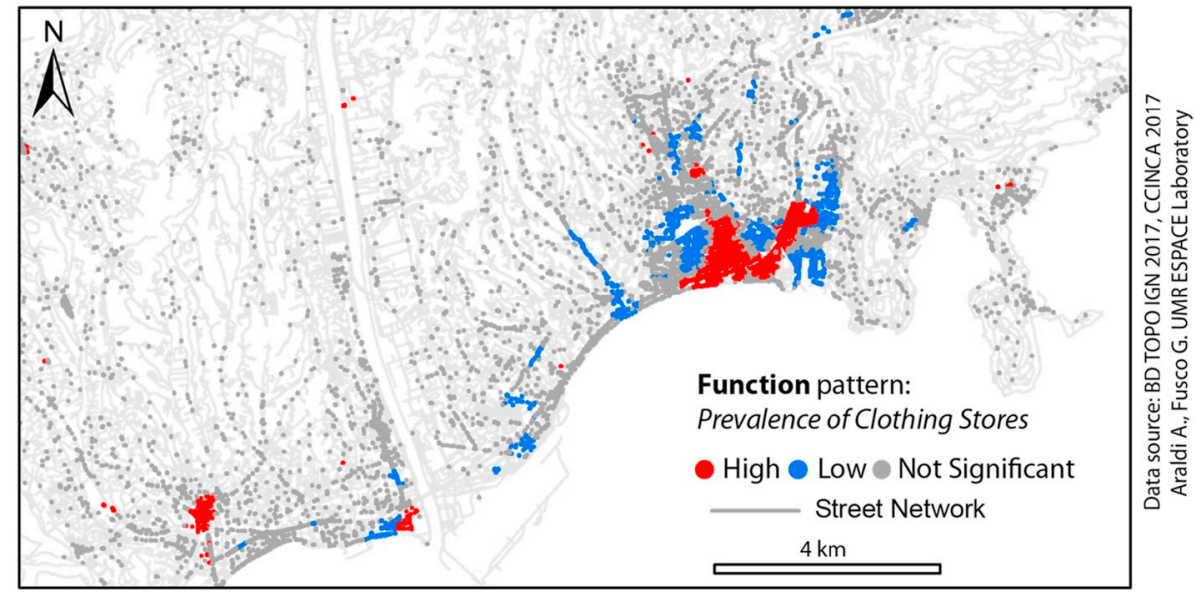

Fig. 6. Example of Function Pattern: prevalence of clothing stores.

groups of individuals sharing a few key characteristics, which could vary from one group to the other. As observed by Mackaness and Chaudhry (2011), Bayesian clustering methods in retailing studies might be a good option considering the fuzzy and incomplete knowledge of the domain.

The careful theory-driven feature selection of our analysis justifies the use of a simple naïf Bayesian classifier on the 27 morpho-functional indicators. As in Araldi and Fusco (2017), Bayesian clustering is applied on categorical values resulting from geostatistical analysis and morphological-based segmentation, instead of raw indicator values.

Using different random seeds, 1000-step random walks explored the solution space to obtain optimal Bayesian clustering of our spatial units. The search constraints were a minimum cluster content of $2 \%$ of the spatial units, a minimum average probability of assignment of units to each cluster of 0.9 and a maximum of 25 clusters. The optimal score (combining log-likelihood of the clustering solution given the data and a penalization for the increasing number of clusters) was found for the 19-cluster solution. A successive refining phase of the 19-cluster solution was carried out by imposing this fixed number of clusters to 6 independent random walks. The best result shows a contingency table fit score of $67.77 \%$. By construction, the 19 clusters are spatially coherent retail fabrics. Projected in geographic space, they offer a synthetic model of retailscapes within a vast metropolitan area.

The relatively important number of classes identified by the Bayesian clustering is a consequence of the variability within the set of indicators and their internal distribution. A correct number of classes is 
Table 1

Form and function measures implemented in Retail Fabric Assessment methodology.

\begin{tabular}{|c|c|c|c|}
\hline Aspect & Indicator & & Pattern \\
\hline \multirow[t]{8}{*}{ Form } & \multirow[t]{3}{*}{ Distribution } & Total number of stores within $150 \mathrm{~m}$ & $\begin{array}{l}\text { Relative high/average/low store presence at the street } \\
\text { level }\end{array}$ \\
\hline & & Total number of stores within $300 \mathrm{~m}$ & $\begin{array}{l}\text { Relative high/average/low store presence at the } \\
\text { neighborhood level }\end{array}$ \\
\hline & & Total number of stores within $600 \mathrm{~m}$ & $\begin{array}{l}\text { Relative high/average/low store presence at the } \\
\text { community level }\end{array}$ \\
\hline & \multirow[t]{2}{*}{ Agglomeration } & Ratio n. stores $150 \mathrm{~m} / \mathrm{n}$. stores $300 \mathrm{~m}$ & $\begin{array}{l}\mathrm{H}-\mathrm{L}, \mathrm{L}-\mathrm{H} \text {, constant agglomeration between street and } \\
\text { neighborhood levels }\end{array}$ \\
\hline & & Ratio n. stores $300 \mathrm{~m} / \mathrm{n}$. stores $600 \mathrm{~m}$ & $\begin{array}{l}\mathrm{H}-\mathrm{L}, \mathrm{L}-\mathrm{H} \text {, constant agglomeration between neighborhood } \\
\text { and community levels }\end{array}$ \\
\hline & \multirow[t]{3}{*}{ Geometry } & Spatial layout of stores within $150 \mathrm{~m}$ & Fragmented/continuous stores lay out at the street level \\
\hline & & Spatial layout of stores within $300 \mathrm{~m}$ & $\begin{array}{l}\text { Scattered-Linear-Pervasive stores lay out at the } \\
\text { neighborhood level }\end{array}$ \\
\hline & & Spatial layout of stores within $600 \mathrm{~m}$ & $\begin{array}{l}\text { Scattered-Linear-Pervasive stores lay out at the community } \\
\text { level }\end{array}$ \\
\hline \multirow[t]{17}{*}{ Functioning } & Variety & Number of retail categories within $300 \mathrm{~m}$ & $\begin{array}{l}\text { High/average/low retail variety at the neighborhood level } \\
\text { Prevalence of food stores }\end{array}$ \\
\hline & \multirow{13}{*}{ Retail category prevalence } & \multirow{12}{*}{$\begin{array}{l}\text { Ratio between the } n^{\circ} \text { of stores of category(i) and total } n^{\circ} \text { of stores } \\
\text { within } 300 m\end{array}$} & Prevalence of clothing stores \\
\hline & & & Prevalence of furniture related stores \\
\hline & & & Prevalence of vehicle related stores \\
\hline & & & Prevalence of bar and restaurant \\
\hline & & & Prevalence of hotels \\
\hline & & & Prevalence of bank and insurance services \\
\hline & & & Prevalence of real estate agencies \\
\hline & & & Prevalence of informatics and communication stores \\
\hline & & & Prevalence of beauty and health services/stores \\
\hline & & & Prevalence of reparation services \\
\hline & & & Prevalence of culture and leisure services/stores \\
\hline & & & Prevalence of food anchor stores \\
\hline & & \multirow{4}{*}{$\begin{array}{l}\text { Ratio between the surface of anchor stores of category(i) and total } \\
\text { surface of anchor stores within } 600 \mathrm{~m}\end{array}$} & Prevalence of clothing anchor stores \\
\hline & \multirow[t]{3}{*}{$\begin{array}{l}\text { Anchor store category } \\
\text { prevalence }\end{array}$} & & $\begin{array}{l}\text { Prevalence of furniture related anchor stores Prevalence of } \\
\text { vehicle related anchor stores }\end{array}$ \\
\hline & & & Prevalence of home hardware anchor stores \\
\hline & & & Prevalence of culture and leisure anchor stores \\
\hline
\end{tabular}

not determinable a priori. As observed by DeLisle (2005) a "dynamic tension between too few and too many classes" exists when applying classifications to retail activities. The applied Bayesian protocol is an attempt to use unambiguous, meaningful and measurable metrics to obtain an acceptable compromise.

\section{Results and discussion}

The main result of the Bayesian classification is represented by the assignment of each individual store to its most probable cluster. In addition, a rich set of probabilistic information is provided to the analyst to identify and to describe each class. Describing the precise profile of each retail fabric (RF) obtained goes beyond the aim of this paper. In this section we will focus on a few key characteristics and on the spatial arrangement of these patterns showing important recurrences of these structures of retail fabrics within the study area.

Within the French Riviera conurbation, four main centers are identified: (from east to west) Menton, Nice, Antibes and Cannes (the last three are shown in Fig. 7). Stores within these cities, show a highly concentrated, continuous and pervasive pattern. This spatial form characteristic represents the necessary condition allowing functional grouping of stores. The coalescence of nucleated facilities within these cities might find its causes in historical, economic, social, urban characteristics. For example, in all the historical centers of these cities two classes identify a retail fabric composed by small stores related to the high level of tourism-related activity: the first RF1 shows a concentration of restaurants and clothing while the second RF2, is more related to cultural and leisure activities. These retail fabrics do not include large surface stores, probably due to the physical urban constrains (small surfaces and high building fragmentation). Other concentrations recognizable in all these cities are the clothing-oriented districts RF3 and the service-oriented districts RF4. Close to train stations, (as in Nice and
Antibes) service-oriented retail fabric coexist together with high presence of fast-foods, restaurants and food anchor stores RF5. Individual characteristics of each city result in specific patterns: the west side of the clothes district in Nice shares the urban space with a significant concentration of real estate agencies RF6. A similar behavior is noticeable within the core of the clothes district of Cannes, where banks, insurances, real estate agencies and clothing department stores coexist. RF7 (Fig. 6).

When the extension of the city core is important, as in Cannes and even more in Nice, these nucleated specializations are surrounded by a more residential retail fabric characterized by a high variety of retail categories, absence of clothing department stores and the presence of large food stores. This retail fabric is defined by two classes: despite the fact that the functional characterization remains the same, one class RF8 is characterized by a continuous linear distribution and con-centration on main axes while the second RF9 presents fragmentation along the streets (Fig. 7).

When considering smaller cities and community-level agglomerations, the reduced extension of their cores does not allow retailers to give birth to functional clusters. The retail fabric of these settlements RF10 is characterized by high variety of small stores, prevalence of food, clothing, health/beauty stores and few large food stores. This retail nucleated fabric is typical of small-sized cities as Saint-Laurentdu-Var, Cagnes-sur-Mer, Vence, Mandelieu, Beaulieu (Fig. 8a).

Outside the core of both larger and smaller cities, suburban residential ribbons spread in different directions following the main road axes or constrained by the topography of the site (RF11). Within these linear configurations, a good mix of small retail activities is observable, combined with the presence of food, vehicle and hardware anchor stores. These residential ribbons alternate with service oriented ribbons: both share the same form characteristics while the second presents more services and the absence of large stores RF12. These two 


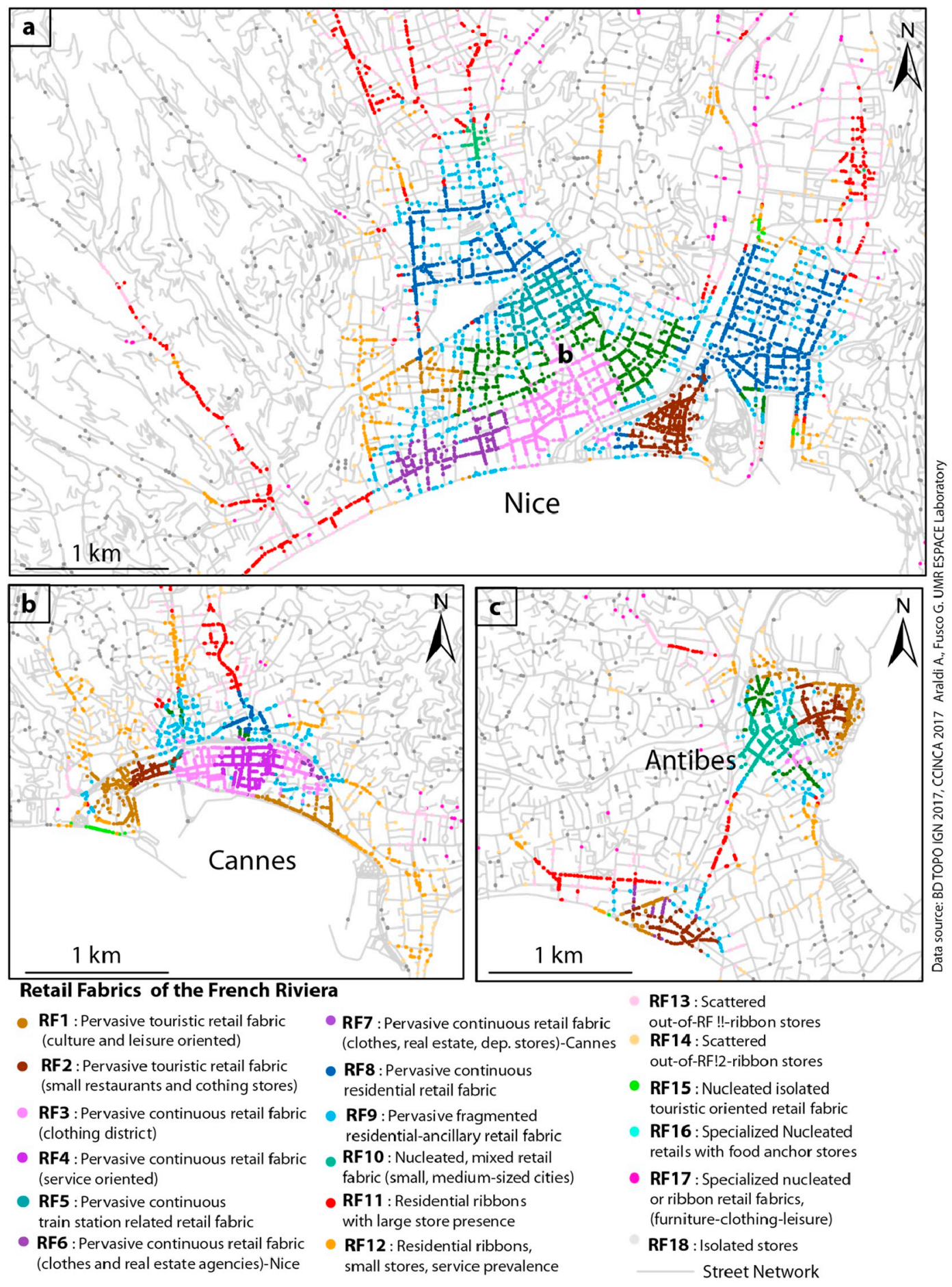

\section{the core of three cities of the Frerch Riviera (Nice, Cannes and Antibes)}

Fig. 7. Retail Fabric Assessment (RFA) results: classification of the retail distribution within the core of three cities of the French Riviera (Nice, Cannes and Antibes).

ribbon configurations are the commercial backbones for more locally scattered/fragmented retail fabrics, named out-of-ribbons (RF13 and RF14).

Small isolated historical villages within the French Riviera, represent another attractive destination for tourists. The commercial offer within villages as Eze, Saint-Paul-de-Vence, Valbonne etc. is highly concentrated, mainly based on restaurants, with an average variety of retail offer and absence of large stores (RF15). The same retail fabric is identified around the marinas of Menton, Saint-Laurent-du-Var, GolfeJuan, Nice (east side) and in small villages along the coast like Juan-lePin, Villefranche-sur-Mer and Cros-de-Cagnes, (old fishing villages, now local touristic hotspots, Fig. 8b).

Two classes represent specialized areas in suburbs where big box stores and shopping malls are predominant. The shape and configura-tion of these patterns is strongly defined by the topography. The retail family (RF16) is composed by isolated concentrations of stores attracted 

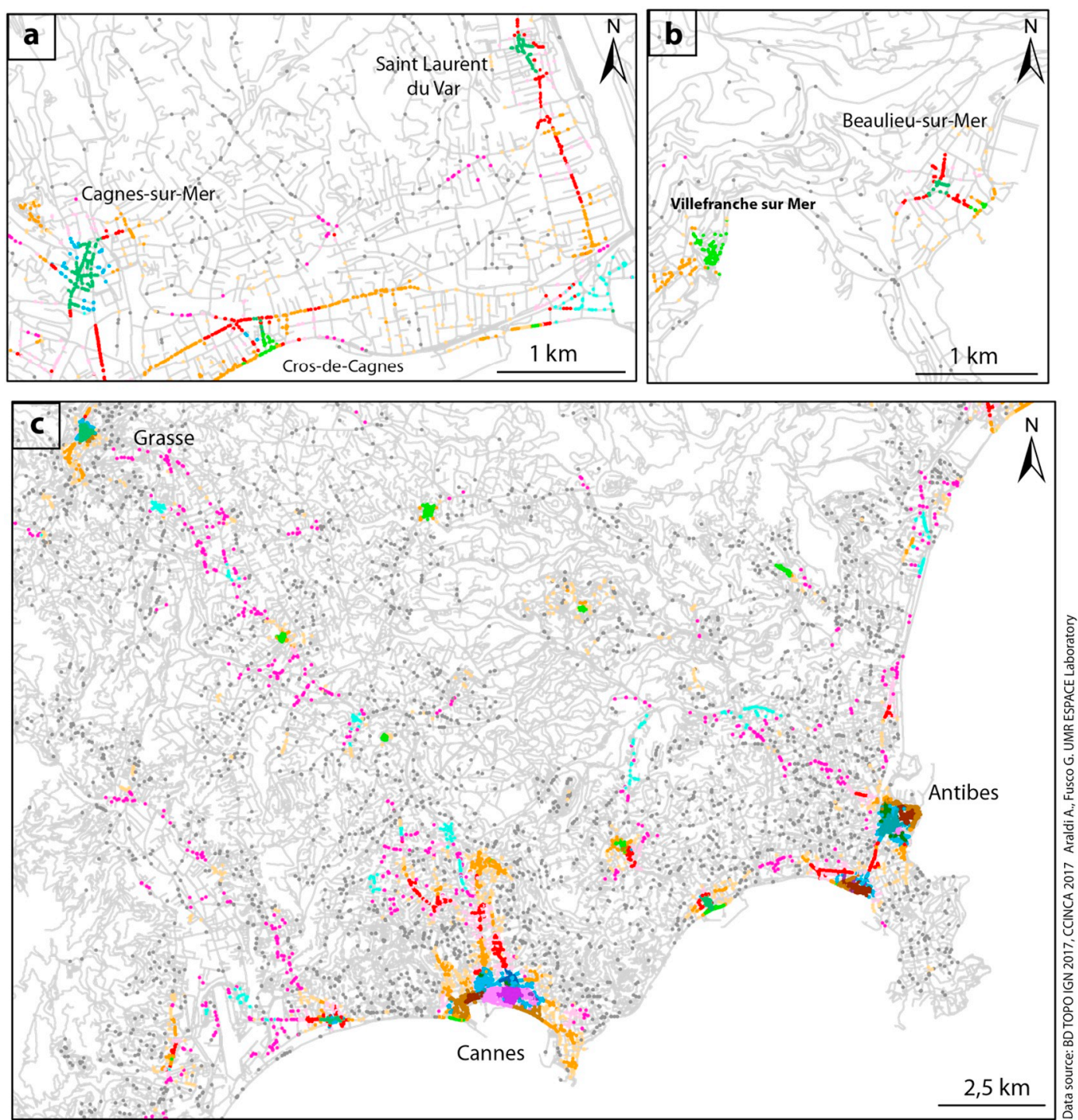

Retail Fabrics of the French Riviera

- RF1 : Pervasive touristic retail fabric (culture and leisure oriented)

- RF2 : Pervasive touristic retail fabric (small restaurants and cothing stores)

- RF3 : Pervasive continuous retail fabric (clothing district)

- RF4 : Pervasive continuous retail fabric (service oriented)

- RF5 : Pervasive continuous train station related retail fabric

- RF6 : Pervasive continuous retail fabric (clothes and real estate agencies)-Nice
- RF7 : Pervasive continuous retail fabric (clothes, real estate, dep. stores)-Cannes

- RF8 : Pervasive continuous residential retail fabric

RF9 : Pervasive fragmented residential-ancillary retail fabric

RF10 : Nucleated, mixed retail

fabric (small, medium-sized cities)

RF11 : Residential ribbons with large store presence

RF12 : Residential ribbons, small stores, service prevalence
RF13: Scattered

out-of-RF!!-ribbon stores RF14: Scattered out-of-RF!)-ribbon stores

- RF15 : Nucleated isolated touristic oriented retail fabric

- RF16 : Specialized Nucleated retails with food anchor stores

- RF17 : Specialized nucleated or ribbon retail fabrics,

(furniture-clothing-leisure)

RF18: Isolated stores Street Network

Fig. 8. Retail Fabric Assessment (RFA) results: classification of the retail distribution of average-sized cities, isolated touristic villages and specialized suburban districts.

by food anchor stores and vehicle related retailers; (RF17) present a ribbon shape and it is more specialized on furniture, clothes, leisure retailing and it attracts small home-related stores. These two specialized retail fabrics could be found isolated or at the margins of residential ribbons (Fig. 8c).

Finally, class RF18 identifies isolated stores and those stores within a close distance $(600 \mathrm{~m})$ to the retail fabrics described above but without any morpho-functional specific characteristic.

The results discussed in this section are of course linked to the indicators of the analysis. Slightly different results could also be obtained from different parametrizations, or implementation procedures on the same indicators. The attentive theory-based selection and implementation of each indicator adopted in this paper, as well as the results on the case study of the French Riviera, suggest the MFA as a promising robust method for the assessment of retail distribution ana-lysis.

The quality of RFA outcomes could be evaluated when compared to expert-based assessments carried out by local agencies ${ }^{5}$ together with the local chamber of commerce (Agence de Déplacements et d'Aménagement des Alpes-Maritimes, 2012). Within this document, the procedure implemented for the identification of commercial districts

\footnotetext{
${ }^{5}$ Agence de Déplacements et d'Aménagement des Alpes Maritimes (ADAAM)
} 

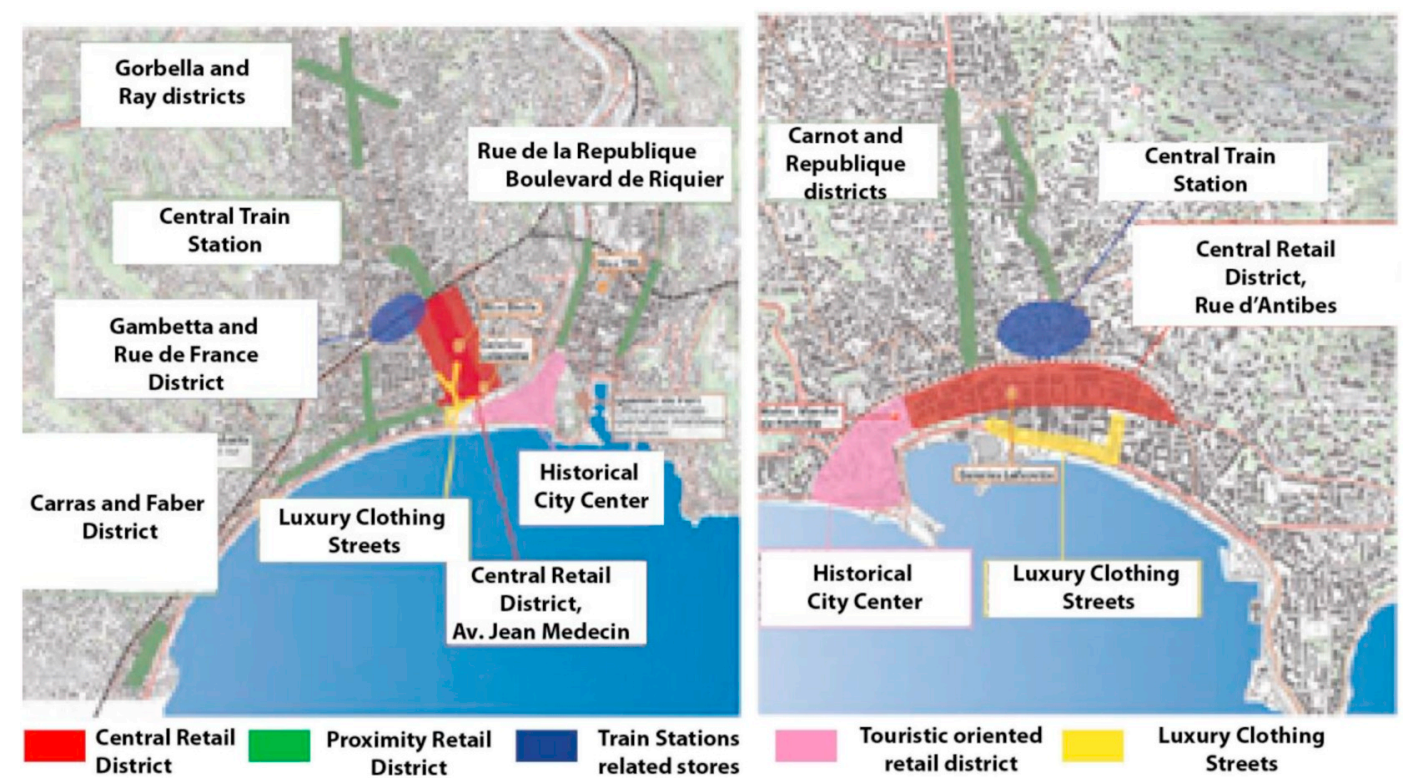

Fig. 9. Retail districts identified by local authorities. Source: Interscot Commerce (2012).

consists in a visual delimitation of retail agglomerations and on the relative expert-based interpretation. Five classes of retail districts are detected by local authorities (Fig. 9): touristic oriented (pink) and proximity retail activities (green) find a straightforward correspondence to some retail fabrics identified through RFA (RF1 and RF2 for the former, RF11 and RF12 for the latter). Within this document, mediumsized cities and small villages are not described while specialized agglomerations are represented by their geographical locations and NAF classification group. The application of RFA allows a finer geographical characterization of all stores in the study areas considering cities of all size and specialized suburban clusters within a common framework. The resulting classification enables the comparison of retail agglomerations between different urban spaces. Moreover, Bayesian probabilities can be used to study both specificities and similarities between classes, combining form and functional aspects. RFA represent an au-tomated and objective methodology providing measures and new in-sights in retail agglomeration analysis.

\section{Conclusions and perspectives}

We proposed a multi-step geoprocessing approach to identify retail districts in a vast metropolitan area. It integrates a theory-based matrix of morpho-functional indicators taking into account the micro retail location, network-constrained geo-statistics and Bayesian clustering. The method proved successful in identifying retail district typologies and their spatial arrangements in the real-world case of the French Riviera metropolitan area, even if the clustering results deserve a more attentive analysis from an economic geographical perspective. The heterogeneity and polycentrism of the coastal region analyzed proved the capacity of MFA method to detect a wide range of commercial districts providing a complete analysis of the retail fabric for both central and peripheral areas.

The retail patterns identified on the French Riviera are clearly specific to this case study. The RFA methodology is nevertheless applicable to other case studies, opening the way to a more objective comparative analysis of the geography of retail patterns within world cities. Brown's and Berry's models represent the theoretical foundation of the RFA procedure: these theories have been developed and discussed along the last century considering European and North American case studies. With a few adaptations, RFA might nevertheless help in describing and defining new theoretical models for non-western countries. For example, in the Japanese and Korean context it is well known that retailers are not limited to the ground floor: the vertical dimension of retail distribution represents an important aspect that should be considered when analyzing the retail fabric of a city (Cho, 2015; Shelton, 1999). The third dimension in these cities correspond to both planned and unplanned commercial centers while in western cities the latter is missing. For far-eastern cities, the RFA indicator of geometry should be thus extended to third dimension, allowing the identification of these specific retail districts. A further aspect that should be considered in far-eastern cities is the anchor role of railway/subway stations. Other examples of local specificities are temple locations in south-east Asia, shopping mall in South America and Turkey, bazars and dubaï in north Africa (Desse \& Lestrade, 2016) etc. RFA has the potential of being adapted to all these case studies with the in-tegration of more specific indicators.

RFA presents several methodological innovations allowing a vast range of applications. The probabilistic content of the Bayesian clustering could be better exploited to identify uncertainties in the knowledge of retail district spatial organization. The bottom-up procedure removes the store district delimitation problem and consequently, the need of an a priori taxonomy of retail agglomerations. This allows the identification of new forms of commerce resulting from current socioeconomic and retail organization evolutions. Improvements should integrate the concept of franchise and standing (as in (Wayens, 2006)). Despite the great interest of these two additional aspects, the data needed for their incorporation in RFA procedure might not be easily collected, limiting applications on comparative diachronic and/or synchronic analysis.

The flexibility of the RFA method, based on its quantitative/objective approach and a minimal dataset requirement, might allow several developments. Future work might consider time series of retail data to study the spatial evolution of commercial districts. The rise and blight of commercial spaces could be studied with a more dynamic approach: delimitating evolving retail areas could help isolating local triggering factors and possible solutions. New form of retail formats and districts emerging from the fast-evolving sector of the retail might be detected through diachronic application of RFA. The perspective is thus open of using RFA analysis to support retail policies in contemporary cities, within wider metropolitan areas.

All these possible applications might bring new empirically-based insights in the elaboration of theoretical commercial distribution models with a transnational approach still respecting regional specificities (see above). 
The assessment of the retailscape could be also used in retailer and consumer behavior geographic studies. For example, in agentbased modeling (Zhu, 2015), this information might represent an environ-mental variable influencing the decision of agents.

Finally, the cross analysis of these results with urban fabric para-meters, street accessibility and centrality values, might highlight in-terrelations between settlement form and commercial functioning. This is a particularly important perspective within our research, linking re-tail policies to urban planning and urban design.

\section{Acknowledgements}

This research was carried out thanks to a research grant of the Nice-Côte d'Azur Chamber of Commerce (CIFRE agreement $\mathrm{N}^{\circ}$ 2015/1478 with UMR ESPACE).

\section{References}

Agence de Déplacements et d'Aménagement des Alpes-Maritimes (2012). Interscot.

Araldi, A., \& Fusco, G. (2017). Decomposing and recomposing urban fabric: The City from the pedestrian point of view. In O. Gervasi, (Vol. Ed.), Computational science and its applications - ICCSA 2017, proceedings, part IV, lecture notes in computer science. 10407. Computational science and its applications - ICCSA 2017, proceedings, part IV, lecture notes in computer science (pp. 365-376).

Araldi, A., \& Fusco, G. (2018). Describing retail agglomeration form in urban space: Local fractal dimension for point pattern analysis on network. Revue Internationale de Géomatique, 28(4) (in press).

Berry, B. J. L. (1963). Commercial structure and commercial blight: Retail patterns and processes in the City of Chicago. Dep. Of geography. University of Chicago Press.

Brown, S. (1991). Retail location: The post hierarchical challenge. The International Review of Retail, Distribution and Consumer Research, 1(3), 367-381.

Brown, S. (1992). Retail location: A micro-scale perspective. Aldershot: Avebury. Brown,

S. (1993). Micro-scale retail location: Cinderella or ugly sister? International Journal of Retail \& Distribution Management, 21(7).

Brown, S. (1994). Retail location at the micro-scale: Inventory and prospect. Service Industries Journal, 14(4), 542-576.

Burns, W. (1959). British shopping centers: New trends in layout and design. London: Leonard Hill.

Cachinho, H. (2014). Consumerscapes and the resilience assessment of urban retail systems. Cities, 36, 131-144.

Carol, H. (1960). The hierarchy of central functions within the city. Annals of the Association of American Geographers, 50(4), 419-438.

Cho, H. H. (2015). Commerces et espaces marchands dans les villes sud coréennes: les centres commerciaux verticaux. PhD thesisUniversité Paris 8www.theses.fr/2015PA080015.

Craig, C. S., Ghosh, A., \& McLafferty, S. (1984). Models of the retail location process: A review. Journal of Retailing, 60(1), 5-35.

Davies, R. L. (1972). Structural models of retail distribution. Transactions of the Institute of British Geographers, 57, 59-82.

Davies, R. L. (1974). Nucleated and ribbon components of the urban retail system in Britain. Town Planning Review, 45, 91-111.

Davies, R. L. (1984). Retail and commercial planning, Croom Helm, Beckenham. Dawson,

J. A. (1983). Shopping centre development. London: Longman.

Dawson, J. A., \& Kirby, D. A. (1980). Urban retail provision and consumer behaviour: Some examples from Western society. In D. T. Herbert, \& R. J. Johnston (Vol. Eds.), Geography and the urban environment: Progress in research and applications. Vol. 3. Geography and the urban environment: Progress in research and applications (pp. 87132). London: John Wiley.

Dawson, J. A., \& Sparks, L. (1986). Issues for the planning of retailing in Scotland. Scottish Planning Law Practice. 18. Scottish Planning Law Practice (pp. 38-40).

Delage, M., \& Fleury, A. (2011). Centralités commerciales et logique hiérarchique en milieu urbain dense: Une démarche renouvelée d'analyse spatiale appliquée au cas de Paris. Bulletin de la Société Géographique de Liège. 56. Bulletin de la Société Géographique de Liège (pp. 7-21). Société Géographique de Liège, $2011<$ halshs-00628436 > .

DeLisle, J. R. (2005). Shopping centre classification: Challenges and opportunities. London: International Council of Shopping Centres Working Paper Series.

Desse, R. P., \& Lestrade, S. (2016). Mutations de l'espace marchand. Presses univ. de Rennes.

Dolega, L., Pavlis, M., \& Singleton, A. (2016). Estimating attractiveness, hierarchy and catchment area extents for a national set of retail center agglomerations. Journal of Retailing and Consumer Services, 28, 78-90.

Duda, R. O., Hart, P. E., \& Stork, D. G. (2001). Pattern classification. NewYork. John Wiley \& Sons.

Duranton, G., \& Overman, H. G. (2005). Testing for localization using micro-geographic data. The Review of Economic Studies, 72(4), 1077-1106.

Fleury, A., Mathian, H., \& Saint-Julien, T. (2012). Définir les centralités commerciales au cœur d'une grande métropole: le cas de Paris intra-muros. Cybergeo, 2012.

Fusco, G. (2016). Beyond the built-up form/mobility relationship: Spatial affordance and lifestyles. Computers, Environment and Urban Systems, 60, 50-66.

Gehl, J. (1987). Life between buildings: Using public space. New York: Van Nostrand Reinhold.

Graff, P. (2000). L'exception urbaine: Nice, de la Renaissance au Consiglio d'Ornato. Ed. Parenthèses.

Greenberg, M. (1995). The poetics of cities: Designing neighborhoods that work. Ohio state. Columbus, OH: University Press.

Guy, C. M. (1984). The urban pattern of retailing: Within the UK. In R. L. Davies, \& D. S. Rogers (Eds.). Store location and store assessment research. Chichester: Wiley.

Guy, C. M. (1994). The retail development process, Routledge, London.

Guy, C. M. (1998). Classifications of retail stores and shopping centres: Some methodological issues. GeoJournal, 45(4), 255-264.

Hidalgo, C. A., \& Castañer, E. E. (2015). The amenity space and the evolution of neighborhoods. (arXiv preprint arXiv:1509.02868).

Hillier, B. (1996). Space is the machine: A configurational theory of architecture. Cambridge: Cambridge University Press.

Hillier, B., et al. (2003). Natural movement: Or, configuration and attraction in urban pedestrian movement. Environment and Planning. B, Planning \& Design, 20(1), 29-66 (1993).

Jacobs, J. (1961). The death and life of great American cities. New York: Random House.

Jensen, P. (2006). Network-based predictions of retail store commercial categories and optimal locations. Physical Review E, 74(3), 035101.

Jones, K., \& Simmons, J. (1990). The retail environment. London: Routledge. Kanevski,

M., \& Pereira, M. G. (2017). Local fractality: The case of forest fires in Portugal. Physica A: Statistical Mechanics and its Applications, 479, 400-410.

Mackaness, W. A., \& Chaudhry, O. Z. (2011). Automatic classification of retail spaces

from a large scale topographic database. Transactions in GIS, 15(3), 291-307. Marcon, E., \& Puech, F. (2009). Measures of the geographic concentration of industries: Improving distance-based methods. Journal of Economic Geography, 10(5), 745-762.

Merenne-Schoumaker, B. (2008). Les dynamiques économiques et les choix de localisation des entreprises et des services. Territoire (s) Wallon (s) Hors série. 2008 57-62.

Okabe, A., \& Funamoto, S. (2000). An exploratory method for detecting multi-level

clumps in the distribution of points-a computational tool, VCM (variable clumping method). Journal of Geographical Systems, 2(2), 111-120.

Okabe, A., \& Yamada, I. (2001). The K-function method on a network and its computational implementation. Geographical Analysis, 33(3), 271-290.

Openshaw, S. (1984). Ecological fallacies and the analysis of areal census data. Environment and Planning A, 16, 17-31.

Porta, S., Strano, E., Iacoviello, V., Messora, R., Latora, V., Cardillo, A., \& Scellato, S. (2009). Street centrality and densities of retail and services in Bologna, Italy. Environment and Planning. B, Planning \& Design, 36(3), 450-465.

Potter, R. B. (1982). The urban retailing system: Location, cognition and behaviour, Aldershot: Gower.

Proudfoot, M. J. (1937). City retail structure. Economic Geography, 13(4), 425-428.

Saraiva, M., \& Pinho, P. (2017). Spatial modelling of commercial spaces in medium-sized cities. GeoJournal, 82(3), 433-454 (2017).

Shelton, B. (1999). Learning from the Japanese city west meets east in urban design. London: E \& FN Spon.

Shiode, S., \& Shiode, N. (2009). Detection of multi-scale clusters in network space. International Journal of Geographical Information Science, 23(1), 75-92.

Vazquez, P. J. (2011). Classification géométrique des espaces commerçants wallons-Vers une objectivation des caractéristiques morphologiques des nodules? Bulletin de la Société Géographique de Liège, 2011, 56.

Wayens, B. (2006). Structures du commerce de détail bruxellois. PhD ThesisUniversité Libre de Bruxelles.

White, L. J. (1975). The spatial distribution of retail firms in an urban setting. Regional Science and Urban Economics, 5, 325-333.

Yamada, I., \& Thill, J. C. (2004). Comparison of planar and network K-functions in traffic accident analysis. Journal of Transport Geography, 12(2), 149-158.

Yoshida, H., \& Omae, M. (2005). An approach for analysis of urban morphology. Computers, Environment and Urban Systems, 29(2), 223-247.

Zhu, W. (2015). Agent-based simulation and modeling of retail center systems. Journal of Urban Planning and Development, 142(1). 